Journal of Applied Fluid Mechanics, Vol. 9, Special Issue 2, pp. 253-258, 2016.

Selected papers from the XIIth Franco - Quebec Inter-University

Symposium on Thermal Systems -2015

Available online at www.jafmonline.net, ISSN 1735-3572, EISSN 1735-3645.

DOI: $10.36884 /$ jafm.9.SI2.25790

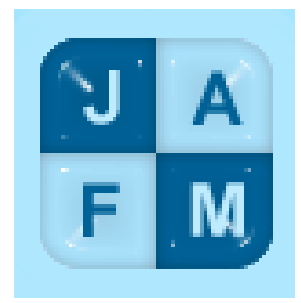

\title{
Experimental Study of Energy Efficiency of a Single Microtube
}

\author{
H. E. Mghari and H. Louahlia-Gualous \\ Caen Normandy University, LUSAC Laboratory, Saint Lô, 120 rue de l'exode, 50000, France \\ †Corresponding Author Email:hasna.louahlia@unicaen.fr
}

(Received October 8, 2015; accepted December 10, 2015)

\begin{abstract}
This paper presents an experimental study of capillary steam condensation in two circular glass microtubes ( $480 \mu \mathrm{m}$ and $280 \mu \mathrm{m}$ diameters). It described the experimental set up and micro instrumentation used to analyze condensation inside a microtube. Experimental results concerns effect of the pressure and cooling heat flux on the condensation flow regimes in microtube. Along the flow direction, annular, slug, plug, mist and bubbly flow patterns are observed in the microtube. Our attention is focused on the analysis of pressure drop, and hydrodynamic characteristics of slug flow because it is one of the basis two-phase flow pattern in condensation inside microchannels.
\end{abstract}

Keywords: Condensation; Microtube; Flow structures; Two-phase flow; Capillary regime.

\section{INTRODUCTION}

In recent years, the need of more efficient heat transfer systems, in order to reduce electricity consumption and $\mathrm{CO} 2$ emissions, has motivated microchannel condensation research and development. New heat exchanger generations are expected to be more effective and compact (towards miniature structures).Condensers with circular and noncircular cross section are being used in numerous applications ranging from automotive space conditioning systems to mobile refrigerated transport. Optimal design of these condensers requires a detailed understanding of condensation heat transfer and pressure drop at small scale. As condensation progresses, various flow regimes are observed resulting from the changes in the relative magnitudes of forces acting upon the phases.

A control-volume numerical approach has been used by Niazmand et al. (2010) to study rarefaction effects in simultaneously hydrodynamically and thermally developing flow in rectangular microchannels. The effects of velocity slip and thermal creep on the twophase flow are examined. Another study is conducted by Boudouh et al. (2015) on the boiling heat transfer coefficients of deionized water and copper oxide water-based nanofluids at different operating conditions.
El Mghari et al. (2014 and 2015) have conducted modeling of steam condensation in triangular, square, and rectangular microchannels and investigated different cross sections and nano-particles effect on the condensation heat transfer coefficient in microchannels. Louahlia-Gualousand Mecheri (2007) and Odaymet and Louahlia-Gualous (2012) have carried out visualization and experiments on steam condensation in a single microchannel. The droplet, annular injection and bubbly flow patterns during condensation in microchannels were observed. Effect of inlet mass flux and microchannel diameters on the two-phase flow regimes, were investigated. Ma et al. (2011) investigated the two-phase flow patterns and transition characteristics for steam condensation in silicon microchannels with different cross-sectional geometries. The flow regime maps for different microchannels during condensation were established versus steam mass flux and steam quality. Kim et al. (2012) studied the flow pattern and pressure drop of FC-72 condensation in square microchannels. Smoothannular, wavy-annular, transition, slug, and bubbly flow regimes were identified.

In this paper, visualization study is conducted to investigate flow regimes of steam condensation in a glass microtube. Pressure drop and temperatures difference induced by condensation are taken into consideration to reveal their influence on those flow patterns. Based on the experimental data, influence of 
the hydraulic diameter, vapor mass velocity and the coolant is established.

\section{EXPERIMENTAL SETUP}

Figure 1a shows the schematic diagram of the experimental set up which consists of an open circuit containing three principal subsystems: a controlled steam generator, a micro-condenser test section, and a system for condensate mass flow rate measurement. Deionized water in the electric steam generator (1) was vaporized at a desired pressure. Saturated vapor was flowed to the electric preheater (6) in order to prevent condensation of vapor inside connecting tubes between the steam generator and inlet of micro condenser test section. A $10 \mu \mathrm{m}$ filter (2) was used to eliminate any dust or micro particles in the working fluid. Vapor mass flow rate at the channel inlet was adjusted through a regulating valve (8). Temperatures at the microchannel inlet and outlet were measured using a $75 \mu$ mmicrothermocouple. At the microchannel entrance, pressure was measured by XPM5 miniature pressure sensor with response time of $2 \mathrm{~ms}$. Steam enters in the micro condenser test section that was cooled by water with a controlled inlet temperature. The cooling system consists of the tank containing thermostatic water (14), a flow meter (16) to measure the volume flow rate of the cooling water with an uncertainty of $4 \%$. At the micro condenser exit, water was cooled in the heat exchanger (12) before returning in the water tank. Vapor flowing the microtube test section, becomes in two-phase flow and it was led into a condenser (13) in which all the stream was completely condensed. The collected liquid was weighed during a known period of time with an electronic balance. The inlet and outlet temperatures of the cooling water were measured through micro thermocouples (K-type, $75 \mathrm{~lm}$ ).

A camera system (Southern Vision System Inc) mounted with a set of microscope lenses is used to record two-phase flow behaviors. Steam temperature and pressure at the entrance and exit of the microtube are monitored by two K-type thermocouples, and two miniature pressure sensors.

The cooling water is provided by a thermostatic water bath (Fisher Scientific) and the flow rate is measured by the flow meter. The entrance and exit temperatures are also texted via two K-type thermocouples micro thermocouples (K-type, $75 \mathrm{~lm}$ ).

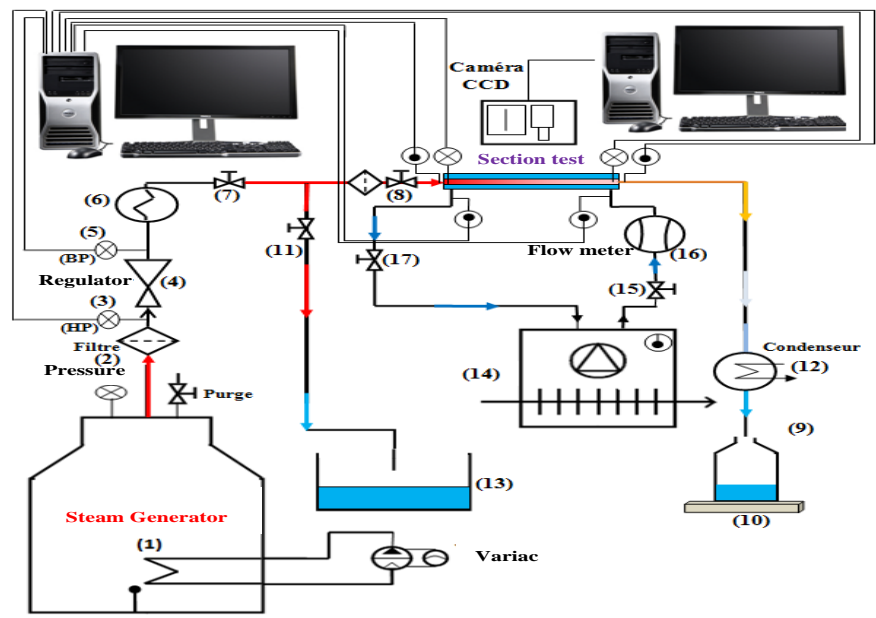

Fig. 1.a. Schematic illustration of the experimental setup.

The test section shown in Fig. 1b has an effective length of $690 \mathrm{~mm}$. The miniature glass tube is cooled using water flowing inside a glass tube of $10 \mathrm{~mm}$ diameter. A convergent was placed at the channel inlet and thereby uniform vapor velocity profile has been assumed at the channel inlet. The condensate flow rate inside the miniature tube is determined from the energy balance on the cooling waterside. The cooling water flow rate is measured using the flow meter. A Labview data acquisition system has been used to record all temperature measurements for each experimental condition.

The inlet steam pressure and the flow rate of the cooling water were regulated during experiments. The outlet condensate flow was at the atmospheric pressure. Different two-phase flows were observed inside the miniature glass tube by varying the cooling heat flow rate or the steam mass flux. Before each experiment, the boiler was discharged in order to evacuate the incondensable gases. All the results presented in this paper were obtained using the pure vapor of distilled water.

\section{RESULTS AND ANALYSIS}

\subsection{Flow pattern visualization}

Steam condensation flow patterns are closely associated with different surface free energy, which is closely with the inlet vapor mass flux, cooling heat, and microchannel geometrical parameters. 
The increase in the vapor condensation rate in the microchannel increases the hydrodynamic instabilities and the slug formation. However, the decrease of the microchannel diameter can capillary regime.

In the present work, several experiments on the visualization of condensation flow in the capillary regimes are conducted by varying the cooling heat, the inlet vapor mass flux and vapor pressure. All these parameters are strongly influenced the condensation rate and the flow structures.

Different condensation flow structures are identified in the microtube: annular flow, churn flow, annular/bubbly, liquid slug-bubbly flow and annular with the production of spherical bubbles flow. Orientation of steam flow in the microtube is from the right to the left in contrast to that of the coolant flow.

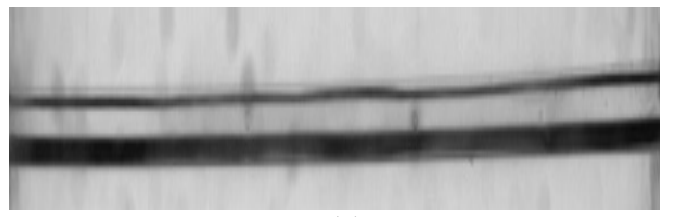

(a)

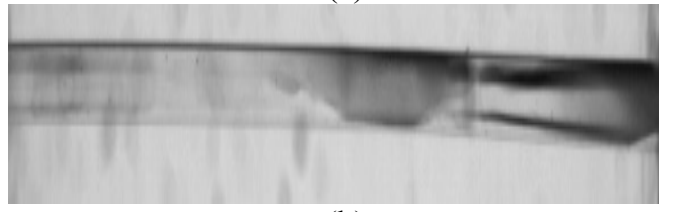

(b)

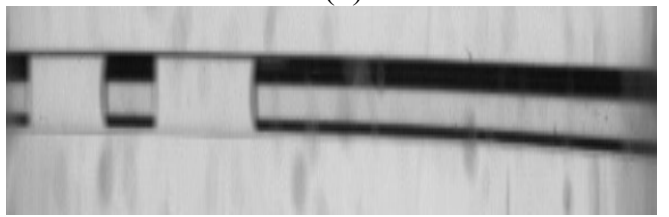

(c)

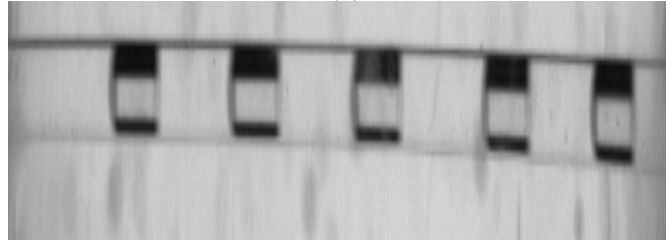

(d)

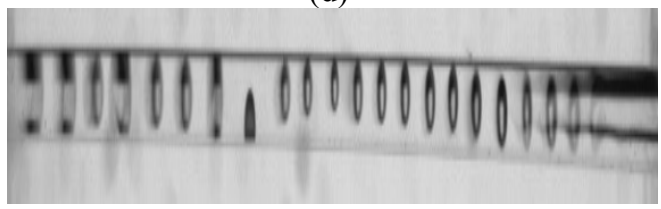

(e)

Fig. 2.Different two-phase flow patterns in a silicon microchannel of $\mathrm{Dh}=408 \mu \mathrm{m}$ : (a) annular flow mist flow, (b)churn flow, (c) annular/ elongated bubbles flow, (e) slug/elongated bubbly flow and (f) annular/bubbles injection flow.

Fig 2 a shows an image of the annular flow that occupies the entire tube where the interfacial frictional forces and inertia are very important. Waves can be formed at the vapor-liquid interface and hence the flow becomes a churn flow (Fig. 2b). These waves caused by the Kelvin-Helmholtz instabilities (Louahlia and Mecheri, 2007). The amplitude of these waves increases over time causing strangling of the central flow of the steam and bubbles injecting which scour the microchannel moving towards the outlet (Fig. 2c). After bubbles injection the annular length decreases under the effect of a decrease of the pressure generated by the bubbles flow at downstream of the microtube exit. Bubble size may be elongated or spherical depending on the flow velocity and the condensation rate (Fig. 2.d-e). Fig. 2d shows the plug flow occupying the entire capillary length. Asnoticed by Odaymet et al. (2012), bubbles size could be increased by reducing the steam mass flux or increasing the cooling heat flux. The sizes of the liquid slug depend on the condensation rate at the bubbles interface.

\subsection{Coolant influence on the bubbles and the pressure drop}

For two different coolant mass flow rates $(3.33$ and 10 $\mathrm{g} / \mathrm{s})$, Figs. 3a-c present influence of the cooling heat flux on: (i) the size and the speed of the plugs (Fig.3 $a-b)$ and (ii) the bubbles course (Fig.3c).

Thus, the slug size increases with cooling heat flux as indicated in Fig. 3a.It can be noticed that when the bubble size is large the corresponding velocity is low as shown in Fig. 3b. Fig 3.c shows that the path of the bubbles decreases over time and increases with the coolant heat flux.

\subsection{Pressure Drop}

Fig. 4 shows that the evolution of total pressure drop increases with the vapor mass flux. The results presented in this figure are obtained for steam condensation in the microtube with diameter of $480 \mu \mathrm{m}$, coolant temperature of $20^{\circ} \mathrm{C}$ and mass flow rate of $6.7 \mathrm{~g} / \mathrm{s}$.

Experimental measurements in $280 \mu \mathrm{m}$ microtube diameter are shown in Fig. 4 and those observed for microtube $480 \mu \mathrm{m}$ diameter microtbe are presented in Fig. 5.It can be seen that pressure drop increases with the vapor mass flux while the condensation flow structures are distinct in both cases. Furthermore, Fig. 5 shows that the pressure

drop is increased by 90 mbar for a vapor mass flux of $130 \mathrm{~kg} / \mathrm{m}^{2} \mathrm{~s}$; and about $600 \mathrm{mbar}$ for a vapor mass flux of $640 \mathrm{~kg} / \mathrm{m}^{2} \mathrm{~s}$. Fig 6 shows that at the microchannel entrance, the pressure and the mean temperature of the steam having the same trends. The temporal distributions obtained for the vapor temperature and pressure appear periodically due to the condensation flow pattern. The obtained two-phase flow structure is periodic, and whose periodicity depends of the bubbles and the slug size that influences their route time as shown in Fig.3.

At the capillary exit, Figures 7 and 8show the outlet pressure and temperature periodicity for two microtube diameters $(280$ and $480 \mu \mathrm{m})$. 
H. E. Mghari and H. Louahlia-Gualous. /JAFM, Vol. 9, Special Issue 2, pp. 253-258, 2016.

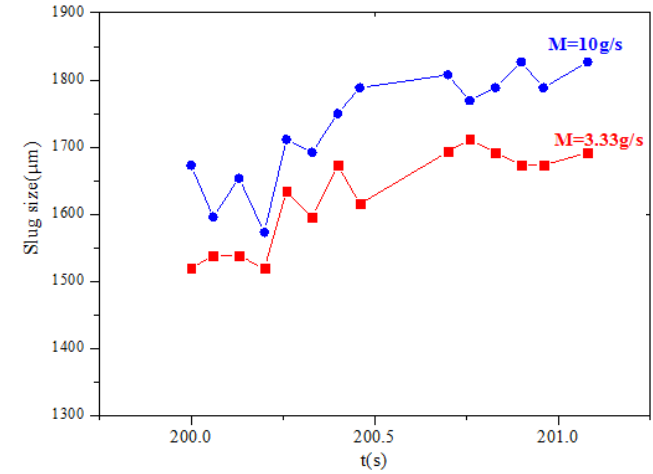

(a)

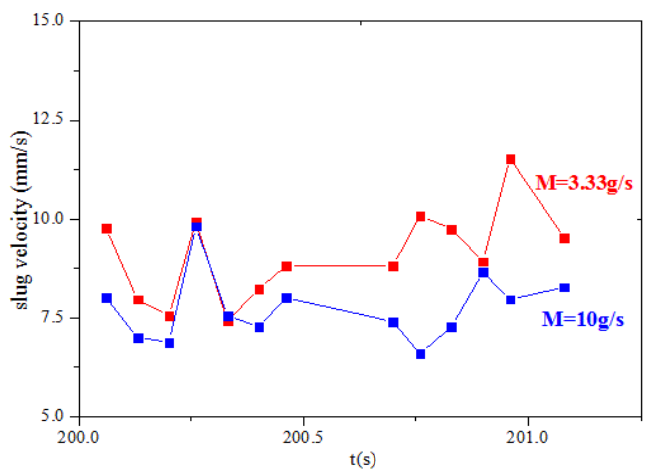

(b)

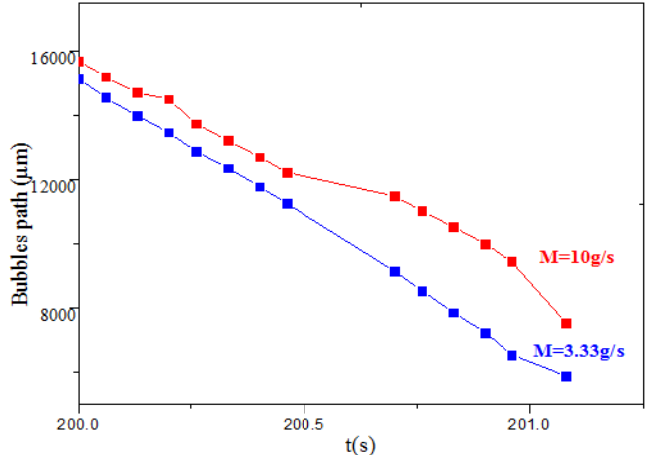

(c)

Fig. 3. Coolant mass flow rate effect on: (a) bubbles size, (b) bubbles velocity, and (c) bubbles path.

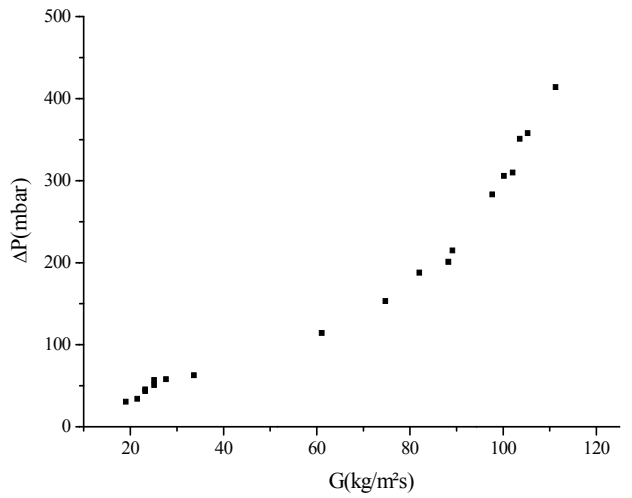

Fig. 4. Inlet vapor mass flux effect on the pressure drop $(480 \mu \mathrm{m}$ microtube diameter).

In either the inlet vapor mass flux is $80.17 \mathrm{~kg} / \mathrm{m}^{2} \mathrm{~s}$, the temperature and the coolant mass flow rate are respectively $20^{\circ} \mathrm{C}$ and $6.7 \mathrm{~g} / \mathrm{s}$.

During this period, condensate flow in microtube changes as described above. It is clear that temperature variation for each period of time is related to condensate flow structure in the microtube. At any time, flow temperature decreases and increases as micro thermocouple is crossed by bubbles or condensate liquid. It is clearly seen that the temporal variation of the flow temperature is related to the structure of condensation flow patterns.

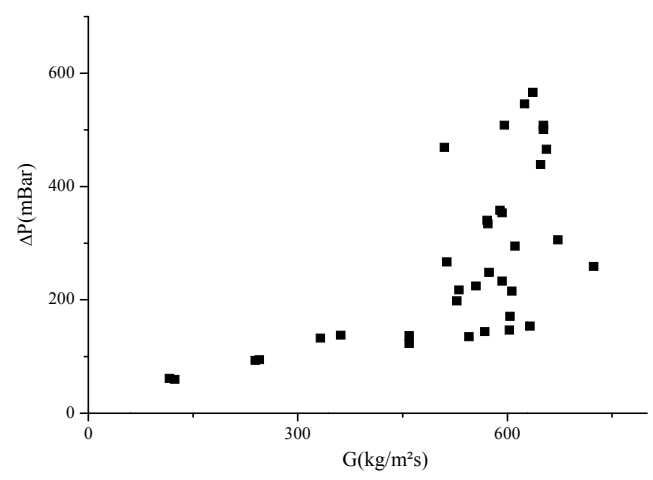

Fig. 5. Pressure drop variation according the inlet vapor mas flux in the microchannel (280 $\mu \mathrm{m}$ microtube diameter).

\section{CONCLUSION}

A visualization and measurement investigation has been conducted to investigate two-phase flow of steam condensation in a single glass microtubes. The flow structures distribution, the pressure and temperature during the condensation process in the microtube are measured. The following conclusions can be drawn from the experimental data:

- Annular, annular-waves, slug, churn, injection, droplet-injection and bubble flow patterns are observed for condensation in the glass microtube 


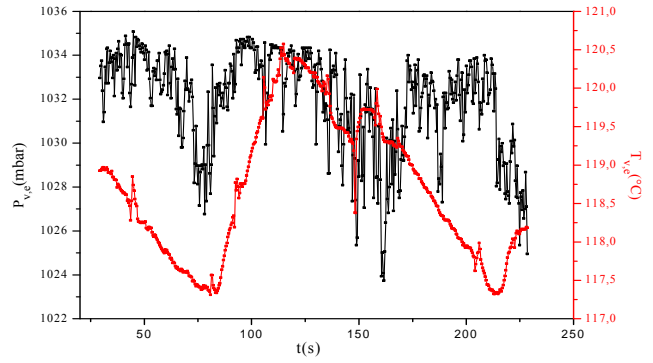

Fig. 6. Inlet vapor pressure drop and temperature in the microtube $(D=280 \mu \mathrm{m})$.

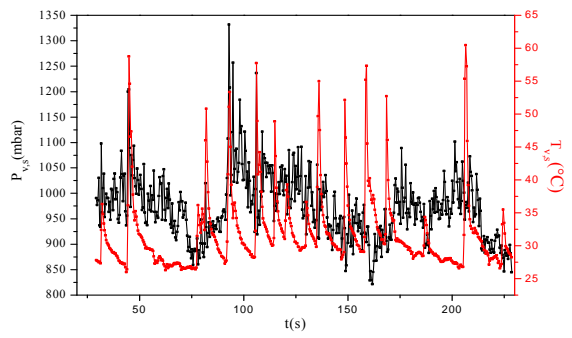

Fig. 7.Outlet vapor pressure drop and temperature in the microchannel $(D=280 \mu \mathrm{m})$.

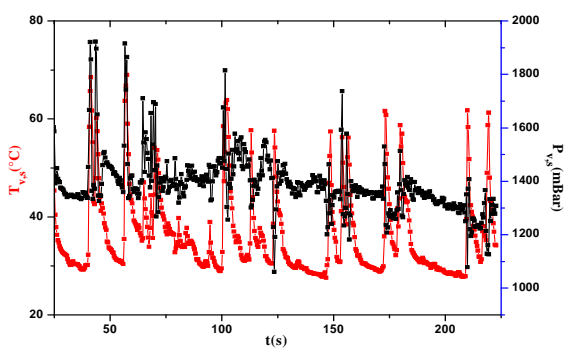

Fig. 8. Outlet vapor pressure drop and temperature in the microchannel $(D=480 ~ \mu m)$.

under variation of inlet vapor mass flux and coolant heat flux.

- Increasing the coolant mass flow rate, bubbles size decreases and slug size increases in the microtube because of the condensate rate that reduces the interfacial force. This last has a crucial role in the mechanisms of capillary forces and shear stresses, causing an increase in the space occupied by vapor flow in the microtube. It also noted, when the capillary and frictional forces increase, bubbles size increases with their travel speeds.

- In the previous work, it noticed that the two-phase frictional pressure drop corresponds roughly to $95 \%$ of the net pressure drop. The results show that the pressure drop increased with increasing mass velocity and decreasing saturation temperature, whereas it is not significantly affected by the coolant.

\section{ACKNOWLEDGEMENTS.}

The financial support of the Saint Lo agglomeration of France and LUSAC laboratory of Caen Normandy University are gratefully acknowledged.

\section{REFERENCES}

Boudouh, M., H. Louahlia-Gualous., and M. De Labachelerie. (2010), Local convective boiling heat transfer and pressure drop of nanofluid in narrow rectangular channels, Applied Thermal Engineering (30), 2619-2631.

El, Mghari H., Asbik M., Louahlia-Gualous H., VoicuI. (2014). Condensation heat transfer enhancement in a horizontal non-circular microchannel. Applied Thermal Engineering, 64.358-370.

El, Mghari H., H. Louahlia-Gualous., and E Lepinasse.(2015).Numerical study of nanofluid condensation heat transfer in a square microchannel.Numerical Heat Transfer, Part A, 68: 1-24.

Kim, S. M., J. Kim, and I. Mudawar. (2012). Flow condensation in parallel micro-channels? Part 1: experimental results and assessment of pressure drop correlations, Int. J. Heat Mass Transfer 55 (4). 971-983.

Louahlia-Gualous, H., and B. Mecheri.(2007), unsteady steam condensation flow patterns inside a miniature tube, Applied Thermal Engineering, (27), 1225-1235.

Ma, X. H., X. G. Fan., Z. Lan, and T.T Hao. (2011). Flow patterns and transition characteristics for steam condensation in silicon microchannels, $J$. Micromech.Microeng.21 (7). 075009.

Niazmand H., A. Amiri, Jaghargh and $M$. Renksizbulut. (2010). Slip-Flow and Heat Transfer in Isoflux Rectangular Microchannels with Thermal Creep Effects. Journal of Applied Fluid Mechanics 3. 2, pp. 33-41.

Odaymet, A., H. Louahlia Gualous, and M. De Labachelerie (2012), Local heat transfer and flow patterns during condensation in a single silicon microchannel, Nanoscale and MicroscaleThermophysical Engineering, (16), 220-241.

Odaymet, A., and H. Louahlia-Gualous. (2012), Experimental study of slug flow for condensation in a single square microchannel, Experimental Thermal and Fluid Science, (38), 1-13.

Wu, H.Y., and P. Cheng. (2005). Condensation flow patterns in silicon microchannels, Int. J. Heat Mass Transfer 48 (11). 2186-2197.

Wu, H.Y., M. M Yu., P Cheng., and X Wu. (2007).Injection flow during steam condensation in silicon microchannels, J. Micromech. Microeng. 17 (8).1618-1627. 
H. E. Mghari and H. Louahlia-Gualous. /JAFM, Vol. 9, Special Issue 2, pp. 253-258, 2016. 